\title{
Reproductive Health Behaviour among In-School and Out-of-School Youth in Kabarole District, Uganda
}

\author{
Bannet Ndyanabangi ${ }^{1}$ Walter Kipp ${ }^{2}$ and Hans-Jochen Diesfeld
}

\begin{abstract}
This study was conducted to elucidate whether in-school adolescents have sexual behavioural patterns that differ from those of out-of-school adolescents. A total of 300 in-school and 256 out-of-school adolescents were interviewed. Condom use was significantly higher among in-school than out-of-school adolescents. In-school adolescents had fewer sexual partners in the previous year and had started sexual activities at a later age than outof-school adolescents. In-school adolescents were more likely to have used modern contraceptive in the past than out-of-school adolescents. We conclude that out-of-school adolescents are less likely to practice safe sex and to use modern family planning methods than in-school adolescents. This indicates the need to provide more information to this group of adolescents. They are traditionally neglected in favour of in-school adolescents, who have greater access to information. (AfrJ Reprod Health 2004; 8[3]:55-67)

\section{RÉSUMÉ}

Les comportements de la santé de reproduction chez les jeunes gens en scolarisation et déscolarisés dans la région de Kabarole. Cette étude a été menée pour voir si les adolescents en scolarisation ont un comportement sexuel qui est différent de celui des adolescents déscolarisés. Trois cent adolescents en milieu scolaire et 256 adolescents en milieu extra-scolaire ont été interviewés. Les adolescents en scolarisation avaient plus l'habitude de se servir des préservatifs que les adolescents qui déscolarisés. Les adolescents en scolarisation avaient moins de partenaires sexuels dans l'année précédente et avaient déjà commencé des activités sexuelles à un âge plus avancé que les adolescents déscolarisés. Les adolescents en scolarisation avaient plus la possibilité d'avoir utilisé les contraceptifs modernes dans le passe que les adolescents déscolarisés. Comme conclusion, nous affirmons que les adolescents déscolarisés ont moins la possibilité d'avoir des rapports sexuels sans danger et d'utiliser les méthodes de planification familiale moderne que les adolescents en scolarisation. Ceci montre la nécessité de donner plus de renseignements à ce groupe d'adolescents. Ils sont traditionnellement négligés en faveur des adolescents qui sont toujours en scolarisation qui ont beaucoup plus d'accès aux renseignements. (Rev Afr Santé Reprod 2004; 8 [3]: 5567)
\end{abstract}

KEY WORDS: Modern contraceptives, HIV/AIDS, reproductive behaviour, adolescents, Uganda

\footnotetext{
'Program Manager, African Youth Alliance Project in Uganda, P. O. Box 10230, Kampala, Uganda. Tel: 25641 258816; Fax: 25641 343011; E-mail: bndyanabangi@aya.or.ug ${ }^{2}$ Associate Professor, Department of Public Health Sciences, Faculty of Medicine and Dentistry, University of Alberta, Edmonton, Canada. ${ }^{3}$ Professor Emeritus for Tropical Public Health, formerly Director of the Department of Tropical Hygiene and Public Health, University of Heidelberg, Leopoldstrasse 6, 682319 Starnberg, Germany. Tel: 498151 12143; Fax: 498151 77378;E-mail:H-J.Diesfeld@urz.uni-heidelberg.de
}

Correspondence: Walter Kipp, Department of Public Health Sciences, 13-103 Clinical Sciences Building, University of Alberta, Edmonton, AlbertaCanada T6G 2G3.Tel:780492 8643;Fax: 780492 0364;E-mail:walter.kipp@ualberta.ca 


\section{Introduction}

Most education programmes on reproductive health aimed at adolescents and young adults have targeted school pupils and students because they are easily accessible. However, as school enrolment is quite low in many subSaharan African countries, the population of out-of-school adolescents presents a substantial proportion of young people. Primary school enrolment in Uganda has increased from 1,297,000 to 2,278,000, and to 2,636,000 by 1980,1989 and 1995 respectively. Although the introduction of universal primary education in 1997 increased school enrolment, $60 \%$ of primary pupils drop out before reaching primary seven, at an approximate age of 1213 years. ${ }^{1}$ This situation is similar in other low-income African countries; in Mali $77 \%$ of all school age children never go to school. ${ }^{2}$ Young girls who are especially vulnerable to HIV/AIDS are even less likely to go to school; in developing countries, overall enrolment in primary education of males is $30 \%$ higher than female enrolment. The dropout rate from schools is also much higher among females due to early pregnancies which often result in individuals being permanently expelled from school. ${ }^{3}$ According to Topouzis, out-of-school youth make up a substantial proportion of young people in rural sub-Saharan Africa. ${ }^{4}$ Thus, since the prevention of HIV/STD transmission in adolescents is one of the primary objectives of HIV/AIDS control programmes, strategies have to be developed to reach young people who are not enrolled in schools. This population may have different knowledge needs. Indeed, it was found that in three districts in Uganda, school children were better informed about HIV/AIDS/STDs than out-of-school youth. ${ }^{4}$
The fact that students receive more information is also reflected in the research about reproductive health as well as other topics. Most studies from sub-Saharan Africa target school children. ${ }^{5,6}$ This is not surprising, considering again the accessibility of school youth compared to youth who are not enrolled in formal educational programmes. School youth have direct access to information, greater opportunities and more choices in life. School youth are also easier to organise and monitor, and for this reason government and non-governmental organisations have targeted them for many programmes such as HIV prevention.

In Uganda, out-of-school teenagers consist of over $50 \%$ of all youth between the ages of 15 and 19 years. Females are by far the majority in this group. ${ }^{1}$ They have little access to information, are often intimidated and lack self-confidence. They rarely have opportunities to learn about health issues and even in the rare instances where sensitisation sessions are held, they are not specifically invited, they are not welcome or involved in the discussions. Topouzis found that out-ofschool youth are reluctant to ask questions in public sessions when they do not understand something. This was especially true for girls. ${ }^{4}$ One study from the United States of America showed that psychological well-being was significantly higher in school attendees than in school dropouts. ${ }^{7}$ In a Nigerian hospital, almost all young patients in the drug rehabilitation programme were school dropouts. ${ }^{8}$ In another Nigerian study, nearly half of the female students interviewed at the secondary and university levels and two thirds of those not currently enrolled in school had been pregnant. 


\section{Aims and Objectives of the Study}

In order to better address the needs of adolescent school dropouts, we conducted a study with the following objectives:

- To identify knowledge and opinions about various issues of sexuality and reproductive health in both in-school and out-of-school adolescents in rural areas of Uganda.

- To identify major sources of information regarding sexuality and reproductive health in both groups.

- To determine high-risk sexual behaviour in both groups.

- To determine use of contraceptive methods in both groups.

Data collection took place in 1995 in Kabarole District, a rural district in western Uganda, during a four-month period. The Republic of Uganda occupies a total land area of $241,139 \mathrm{~km}^{2}$ in the East African region. The country has a total population of 21 million inhabitants, with a female-male ratio of $96: 100$. The population growth is estimated at $2.5 \%$ per year from the last available census data. Uganda has a young population with over $50 \%$ of its population below the age of 15 years. Uganda is one of the least urbanised countries in sub-Saharan Africa. Only 15\% of the population lives in townships, mostly in the national capital, Kampala.

Uganda has been especially hard hit by the HIV/AIDS pandemic. Kabarole District is one of the districts more heavily affected by HIV/AIDS. Sentinel surveillance of pregnant women attending antenatal clinics has been carried out in Kabarole by the District Health Office since 1990 and has shown marked differences in HIV prevalence in relation to geographical location of the health centres; $28 \%$ in urban, $14-18 \%$ in semi-urban or main trading centres and $8-10 \%$ in rural areas. Adeokun found in 1996 that out of 1,036 randomly selected households in Kabarole, 356 (34.4\%) had a family member ill, dying or deceased from an HIV-related illness. The number of HIV affected households in Kabarole was higher than in Masaka and Rukungiri districts. ${ }^{10}$ A similar undesirable situation exists in the Kabarole District family planning services; the contraceptive prevalence rate (CPR) for modern contraceptives was estimated at $5 \%$ in a survey in 1996, which is well below the national level of 10\%." A school health education programme, which focuses on HIV/AIDS prevention and family planning has been operating since 1987. There is no special programme to reduce the risk of HIV transmission for out-of-school youth. Although education for adolescents not enrolled in schools is the responsibility of the general health education programme of the District Health Department in Fort Portal, the district capital, their programmes are mainly geared towards adults.

\section{Methodology}

The study population consisted of both the in and out-of-school youth in Kabarole District between the ages of 12 and 21 years. The study was cross-sectional and descriptive, using quantitative research methods. A semistructured questionnaire was used to interview youth enrolled and not enrolled in schools. A list of all primary and secondary schools in the district was obtained from the 
district education officer. Youth from primary six to secondary six were chosen in order to get individuals in the appropriate age groups. A three-stage cluster sampling was used. Firstly, out of six counties, three were randomly selected. From each of the three counties three secondary schools and one primary school were randomly chosen; and from each school one class was randomly selected and all students available on the date of interview were included. All the schools were located in rural areas. A total of 12 classes with 300 students were included in the study.

Interviews were also conducted with out-of-school youth. A multi-stage random sampling based on the administrative boundaries (first stage county selection, second stage sub-county selection, and third stage parish selection) was used. All villages from one rural parish were included. The community representatives (LC 1, local council for village level) provided comprehensive lists from the last census with all out-of-school youth in the respective age groups. From 12 villages, a total of 289 adolescents were listed for interviews. The questionnaire was in the local language (Luganda) and pre-tested in primary and secondary schools twice with five students each time. It was also pre-tested with five outof-school youth. After each pre-testing the questionnaire was edited and adapted to improve the comprehension of the questions. Main areas covered in the questionnaire were demographic and socio-economic data and information on sexual knowledge, attitudes and sexual behaviour.

Three young male and three young female research assistants helped with the interviews. They were selected from 21 students who applied for the positions. The selection criteria included previous experience as research assistants and highest scores on a written test about basic research questions. Training of the research assistants as interviewers followed the guidelines of provided in the Practical Guide for Health Workers on Interviewing and Recording of Community Health Surveys. ${ }^{12}$ The training session lasted three days.

Results were recorded on prepared questionnaire forms. The questionnaires were coded and analysed with EPI INFO version 6.0 and STATA version 5.0. Statistical analysis was done using t-test, chi-square and chi-square for trend tests and Fischer's exact test. Significance level was set at 0.05 .

Written consent for the study was obtained from the district authorities (the district medical officer and the district education officer) and from the headmasters of the schools involved in the study. The purpose of the study was explained to the students and to every individual who participated in the study. Verbal consent was also obtained and recorded on the questionnaires. In order to keep results anonymous, no names were recorded on the data collection sheets. As many participants were under the age of 18 years, parents' consent was required. We followed the procedure that had been used in the district before and which had been accepted in earlier studies. The headmasters of the schools gave consent on behalf of the parents. In the villages where out-of-school youth were interviewed, the LC1 representative gave consent on behalf of the community. The National Council for Science and Technology and the Ministry of Health approved the study protocol. 


\section{Results}

Out of 289 out-of-school adolescents, 256 (88.6\%) completed the interviews, while 300 $(92 \%)$ of the 326 in-school adolescents completed the interviews. The demographic characteristics of respondents are shown in Table 1.
No major differences were observed in the two groups in response to questions relating to perceptions about reproductive health. In both groups, most participants felt that young people have a right to have sexual relations. In both groups the most appropriate age identified for beginning sexual activities was 15 years. Only $1 \%$ of the out-of-school respondents said one should

Table 1 Demographic Characteristics of Respondents

\begin{tabular}{lrr}
\hline Demographic variable & In-school youth $(\mathbf{n}=\mathbf{3 0 0})$ & Out-of-school youth (n=256) \\
\hline Age (years) & Mean 15.3, range $12-21$ & Mean 15.5, range 12-21 \\
Male & $195(65 \%)$ & $171(67 \%)$ \\
Female & $105(35 \%)$ & $85(33 \%)$ \\
Catholic & $93(31 \%)$ & $169(66 \%)$ \\
Protestant & $174(58 \%)$ & $87(24 \%)$ \\
Muslim & $24(8 \%)$ & $8(3 \%)$ \\
Others & $9(3 \%)$ & $18(7 \%)$ \\
Geographical location & Rural & Rural \\
\hline
\end{tabular}

Table 2 Source of Information on Reproductive Health

\begin{tabular}{lrr}
\hline Source & In-school youth (\%) & Out-of-school youth (\%) \\
\hline Parent & $84(25)$ & $9(3)$ \\
Sibling & $177(53)$ & $99(37)$ \\
Older friend & $188(57)$ & $74(29)$ \\
Peers & $28(8)$ & $177(69)$ \\
Teacher & $120(36)$ & - \\
Radio & $202(61)$ & $2(1)$ \\
\hline
\end{tabular}

\section{Multiple answers possible}

Age distribution was very similar in both groups. There was a slight overrepresentation of the age group from 12-13 years among in-school adolescents (7\% vs. $2 \%)$, which is reflected in the slightly higher mean age of the out-of-school group. There were marked differences in the religious status not be sexually active before marriage. There was an overwhelming demand for more information or teaching sessions on reproductive health matters in both groups (97\% vs. $93 \%$ ).

Out-of-school youth had a less positive attitude towards the use of condoms, with $67 \%$ of participants saying that they would 
use condoms, compared to $86 \%$ in the inschool youth. Their responses on sources of information on reproductive health are recorded in Table 2.

One hundred and ninety five $(65 \%)$ of in-school adolescents reported being sexually active, while 196 (75\%) out-of-school adolescents said they had started having sex ( $\mathrm{p} \geq 0.12$ ). Only 56 (19\%) in-school youth said they had sexual contact in the past 12 months. The figure was much higher for outof-school youth; 145 (74\%) reported that they
Twelve per cent of out-of-school youth reported the use of force by an adult in their first sexual encounter ( $27 \%$ female, $5 \%$ male). This question was not asked for in-school youth because of some concerns by the headmasters of the schools.

The reported sexual activity in the past 12 months among in-school and out-ofschool youth is shown in Table 3. A significant difference in the trend of sexual activity in both groups was observed, indicating that out-of-school adolescents

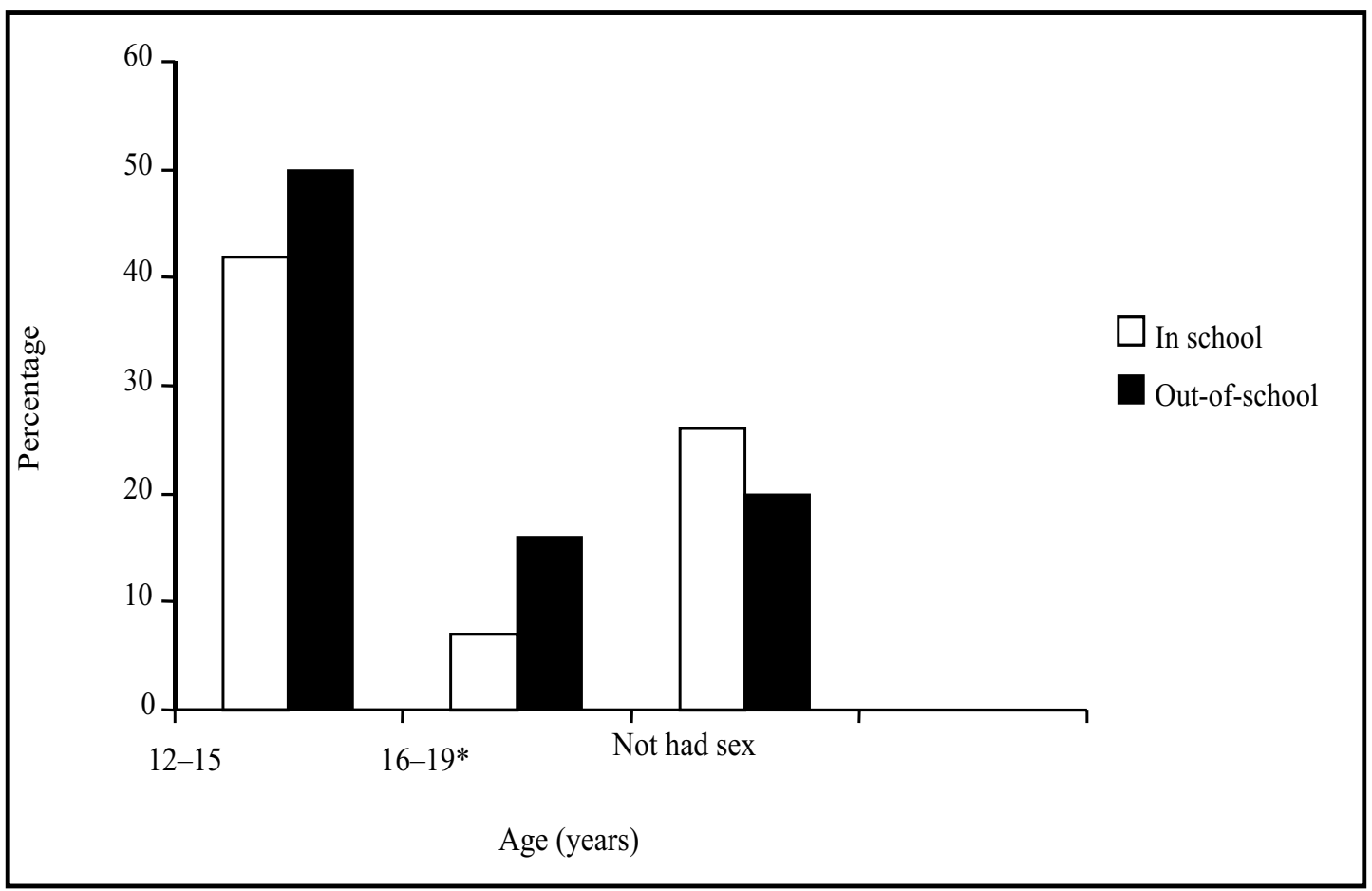

Figure 1 Mean Age of Respondents at First Sexual Intercourse $\left({ }^{*} p<0.069\right)$

had been sexually active in the past 12 months $(p<0.001)$. Age at first sexual encounter was significantly higher among in-school than were more sexually active and had more sexual partners in the past 12 months than inschool adolescents. 
Table 3 Sexual Activity in the Last Twelve Months among the Respondents

\begin{tabular}{lrrr}
\hline & In-school youth $(\mathbf{n}=\mathbf{1 1 7})$ & Out-of-school youth $(\mathbf{n}=\mathbf{2 7 4})$ & Total \\
\hline Not sexually active & $61(52 \%)$ & $78(35 \%)$ & 139 \\
One partner & $41(35 \%)$ & $96(43 \%)$ & 137 \\
Two or more partners & $15(13 \%)$ & $49(22 \%)$ & 64 \\
Total & $117(100 \%)$ & $223(100 \%)$ & 340 \\
\hline
\end{tabular}

Chi square for trend $p=0.400$, indicating statistically significant different trends in both groups

There were marked differences in the knowledge and practice of modern family planning methods between the two groups. Knowledge was significantly lower among out-of-school adolescents, who also had used family planning methods less frequently than in-school adolescents. This is shown in Figure 2.

Knowledge in both modern and traditional family planning methods (e.g., use of herbs) was higher among in-school than to out-of-school youth. The difference was more pronounced regarding modern family planning methods especially condom knowledge. Less than half of the out-ofschool youth were knowledgeable about condoms, while most of the in-school youth had a high knowledge of the condom.

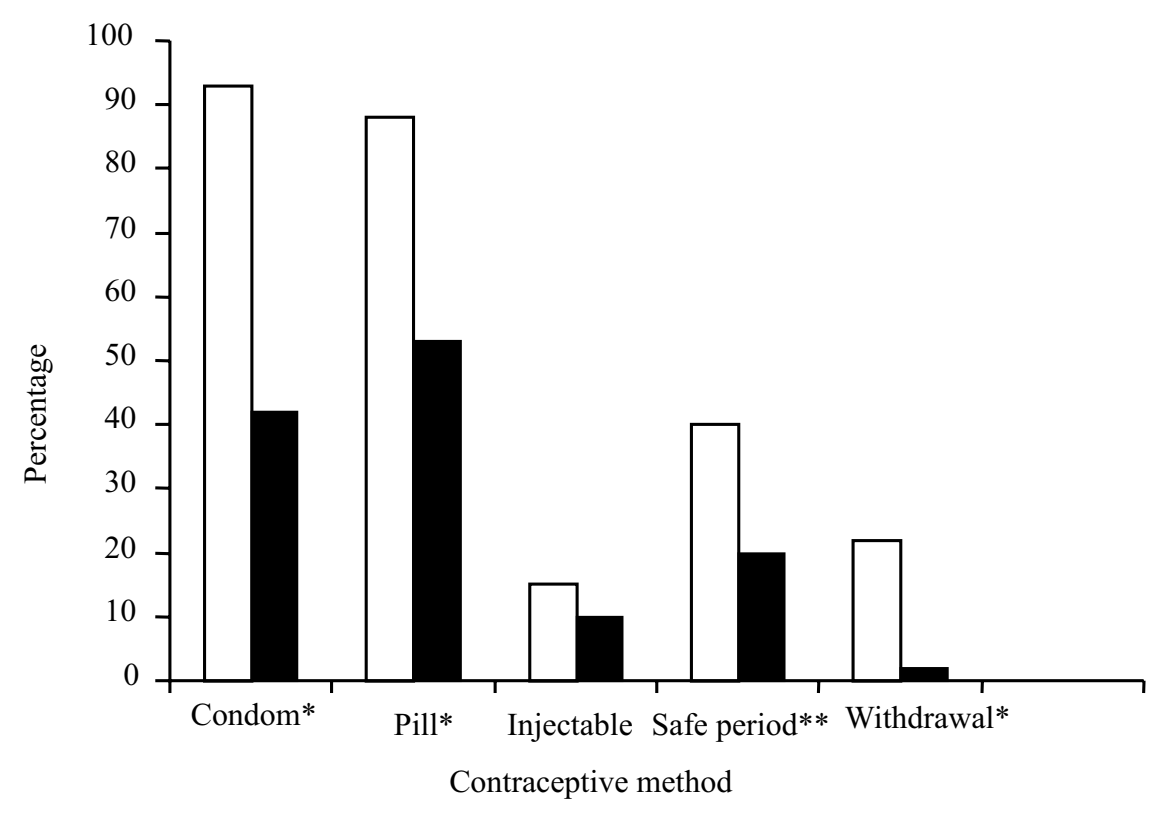

Figure 2 Contraceptive Knowledge of Respondents $\left({ }^{*} \mathrm{p}<0.001,{ }^{* *} \mathrm{p}<0.05\right)$ 
Use of family planning methods was also significantly higher among in-school adolescents. One hundred and nineteen $(61 \%)$ of the sexually active in-school youth reported having ever used a family planning method, while only 33 (17\%) of the sexually active out-of-school youth said they had ever used a family planning method ( $\mathrm{p}<0.001)$. The differences in both groups for the various modern family planning methods are shown in Figure 3.
The biggest difference in contraceptive methods used between the two groups was found in the rates for condom use. It was followed by the use of pills, safe period, withdrawal and injectables. All differences were significant with $\mathrm{p}$ values of less than 0.001 except for injectables $(\mathrm{p}<0.023$, Fischer's exact test, two-tailed). Participants in both groups, but more in the out-of-school group, stated that oral contraceptives are dangerous for the health of the women and can lead to malformation of newborns.

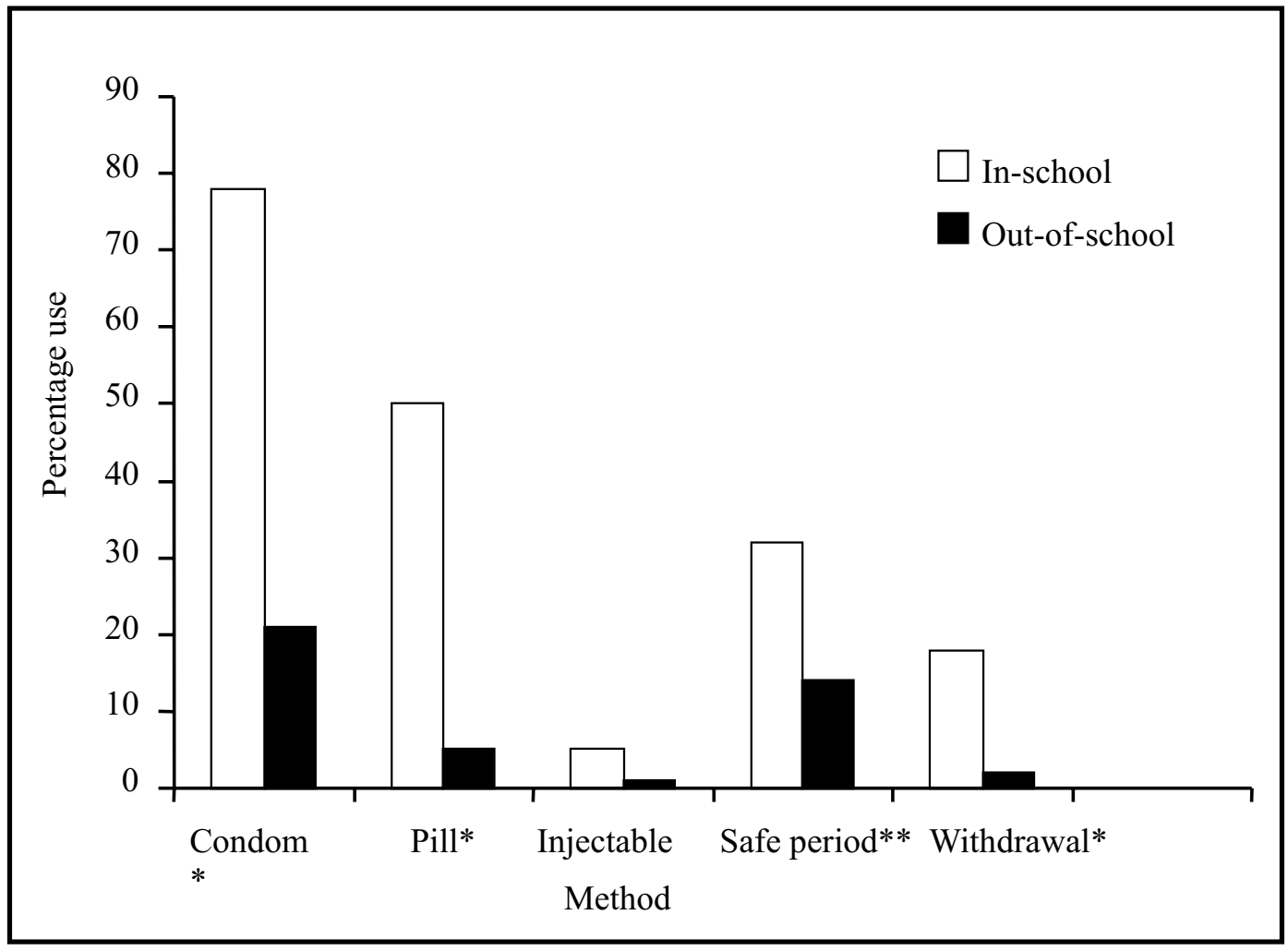

Figure 3 Ever-Use of Contraceptives among Sexually Active Respondents $\left({ }^{*} \mathrm{p}>0.001,{ }^{* *} \mathrm{p}<0.05\right)$ 
When participants were asked if they knew a friend who had an abortion, 168 (56\%) students said yes. The response was, however, lower among out-of-school youth; only $16 \%$ knew of a pregnant friend who had an abortion. Schoolgirls were more likely to be asked to leave home if they became pregnant ( $8 \%$ vs. $2 \%$ ). On the other hand, $43 \%$ of in-school youth reported that they knew a schoolmate who was expelled from school after becoming pregnant.

Gender specific analysis revealed that all differences detected in both samples were also detected in the sub-groups of males and females in each sample. Important differences observed were: (1) higher condom use was reported by boys than girls; (2) reported use of oral contraceptives was higher among girls than boys; and (3) misconceptions about oral contraceptives were lower among boys than girls. However, knowledge about general family planning was lower among boys than girls.

\section{Discussion}

We compared the knowledge and reproductive behaviour practices of in-school and out-of-school adolescents in Uganda. Our samples were assembled by random cluster sampling. The two samples were comparable in regard to age and sex, but not comparable regarding religious status. More students were Protestant (Anglican) while more of the out-of-school youth belonged to the Catholic Church.

We found a significant difference in the knowledge and practice of reproductive health between in-school and out-of-school adolescents. Knowledge of safe sexual behaviour and family planning issues was significantly lower among out-of-school adolescents. This difference was mostly pronounced regarding the knowledge of condoms and pills, where in-school adolescents had better knowledge about condoms and oral contraceptives than out-ofschool youth. A similarly highly significant difference was found in the reported use of contraceptives; $94 \%$ of the out-of-school youth reported that they never used a modern contraceptive, compared to $45 \%$ of in-school youth (Figure 3).

More of the in-school adolescents had not yet engaged in sexual activity (Figure 1). On average, out-of-school youth had started sexual activities earlier and more of them had had their first sexual experience before the age of 15 years. Out-of-school youth also practised safe sex less often than in-school youth. Out-of-school youth were more likely than in-school youth to have had more than one sexual partner in the past year and less likely to have used a condom. The finding that out-of-school youth were using condoms less often is better explained by their negative attitude towards condoms than by their limited access to condom outlets. In Kabarole District, accessibility to condoms is similar for both groups, because condoms are not made available on the school campuses.

Differences in reproductive knowledge and behaviour between in-school and out-ofschool youth has been described in previous studies. Our findings correspond with those from other studies; out-of-school youth had less knowledge about health and disease, and were at greater risk of acquiring STD/HIV and less likely to practice birth control. In a 
study in Tanzania, it was found that nonschool enrolment is a potential risk factor for acquiring $\mathrm{HIV}^{13}$ In two studies from Nigeria, it was found that in-school adolescents had significantly higher reproductive knowledge than those not attending schools. ${ }^{8,14}$ However, we did not find any studies elsewhere where such large differences in reproductive behaviour as we found in Kabarole were described. The differences in reproductive knowledge and behaviour between in-school and out-of-school adolescents in our study were very great. For example, ever use of condoms by in-school youth was $78 \%$, and $21 \%$ by out-of-school youth. Ever-use of oral contraceptives was $50 \%$ and $5 \%$ respectively among in-school and out-of-school adolescents.

A relationship between the educational level and HIV-1 prevalence was also found in young pregnant women in Kabarole District. Young pregnant women in the age group 1519 years with a higher educational level had a significantly lower HIV prevalence than those with a lower educational level. ${ }^{15}$ These studies support our finding that non-students (who have a lower educational level than students) are more exposed to the risk of acquiring an STD or HIV/AIDS. The fact that HIV prevalence in Uganda (and in Kabarole District) is declining in urban areas and remaining the same or even increasing in rural areas may be in part explained by the school enrolment and educational levels, which are significantly higher in urban settings.

Of concern is the low knowledge/use of modern contraceptives and the widespread view among adolescents (both in and out-ofschool) that oral contraceptives are dangerous and have many side effects. Few participants knew alternative methods to pills and injectables, such as intrauterine device (IUD), tubal ligation and vasectomy. The limited knowledge/use of modern contraceptives may also explain a high teenage pregnancy rate in Uganda, where $68 \%$ of women under the age of 19 years have already had a child. ${ }^{16}$ Many health professionals in Kabarole District believe that the teenage pregnancy rate in the district is also high, although no detailed information is available. Our findings, which confirm that young people are sexually active with minimal use of modern contraceptives, support the belief that teenage pregnancy is a serious problem in Kabarole. The high sexual activity of out-of-school youth is similar to findings from a Nigerian study, where $80 \%$ of female out-of-school adolescents reported being sexually active.

Our study revealed some degree of sexual abuse especially for females (females $27 \%$ vs. males $5 \%$ ) during the first sexual experience. Very little is known about sexual abuse in children and adolescents in subSaharan Africa. Many professionals estimate the incidence to be high. In Yaounde, Cameroon, the incidence of sexual abuse in children and adolescents was estimated at $2 \%$, girls being twenty times more likely to be affected than males. ${ }^{17}$ Sexual intercourse forced upon adolescents may also predispose to HIV/AIDS in a high HIV prevalence country such as Uganda and contribute to the spread of HIV.

In Kabarole, all schools are part of an ongoing intensive school health education programme that focuses on reproductive health, while little attention is given to similar 
education for out-of-school youth. Therefore, our study actually made a comparison of "inschool youth with programme" versus "out-of school youth without programme". The great differences we found in our two groups might be less in another district/area where both inschool and out-of-school adolescents have access to educational programmes or not. For example, "in-school youth with no programme" versus "out-of-school youth with no programme" or "in-school youth with a programme" versus "out-of-school with a programme" could be potential study groups in other districts/areas. Additional studies conducted under these different circumstances would yield very useful information to answer more questions.

The limitations of our study are:

1. Some participants did not answer all the questions in the questionnaire.

2. We did not carry out a detailed genderrelated analysis and only reported our results for males and females together for both groups. However, all differences in sexual knowledge and behaviour as reported by this study were to some extent generally reported by both males and females.

3. We cannot exclude interview bias, but the intensive training of the interviewers helped to minimise it.

\section{Conclusion}

Out-of-school adolescents in Kabarole District of Uganda are different from inschool youth in the following ways:

1. They know less about reproductive health.

2. They start sexual activities earlier.
3. They are sexually more active.

4. They are at a higher risk for acquiring sexually transmitted diseases including HIV/AIDS.

5. They use modern contraceptives less often.

There are few examples in sub-Saharan Africa of specifically designed adolescentfriendly educational programmes on reproductive health for out-of-school youth. ${ }^{18}$ The striking differences in reproductive knowledge and behaviour between the two groups indicate that there is a great need to generate more appropriate reproductive education programmes in Kabarole specifically for out-of-school adolescents.

We suggest the following possibilities for addressing the reproductive health needs of out-of-school adolescents:

a. Development of a variety of peer education programmes using community-based peers, youth clubs, sport clubs, churches, etc.

b. Development of programmes and counselling services for youth who have been sexually abused, since the majority of these are found among the out-ofschool group. As this is a very sensitive issue, these programmes would have to be carefully designed, taking into account all the cultural and social aspects involved. However, as Uganda is one of the few African countries with an exceptionally open approach to sexual education for adolescents, it could be one of the few countries in sub-Saharan Africa to plan and implement such a programme for this target group. 
Although the above possibilities exist and could be very beneficial, the best option to address the reproductive health needs of outof-school adolescents is to use resources to keep them in school. This would address the general education of more adolescents and at the same time improve their reproductive health status. In the short term this might be done by:

a. Changing policies that favour the expulsion of students from school, when it was known that they had sexual contacts. We found ample evidence in our study that boys who father a child are expelled from school.

b. Changing policies that expel girls from school due to pregnancy and not allowing them to come back after they have delivered their child. This policy is still in place in many African countries.

c. Waiving school fees for primary and secondary education by government or financial support for those who cannot afford to pay school fees. As many school dropouts in sub-Saharan Africa are coming from HIV/AIDS affected families, special schemes (donor and/or government funded) could be set up to financially support students from those families facing financial hardship with special stipends.
There is definitely a need for long-term solution to solve this serious multi-facetted problem. The perspectives that need to be considered include health issues, education issues, gender issues and social responsibilities. Ideally, this problem could be best addressed through multi-sectoral planning and commitment to maximise the use of the scarce resources available.

\section{Acknowledgment}

We would like to thank the Ministry of Health in Uganda for its support in this work and permission for publication. We are indebted to members of the Kabarole District Health Management Team, who gave advice during the conduct of the study and who provided valuable information for the study team. We thank Stan Houston and Jean Kipp for critical comments on the first draft of the manuscript and Regina Goergen for her help in the initial stages of the study. We are indebted to all the participants who took the time to be interviewed. The study was supported by the Federal Republic of Germany through the project PN 87.2591.3 (Basic Health Services, western Uganda). 


\section{REFERENCES}

1. UNICEF. Children and Women in Uganda: $A$ Situation Analysis. Kampala: UNICEF, Uganda, 1997.

2. World Bank. World Development Report. Washington: World Bank, June 1993.

3. Boheene E, Tsodzai J, Hardee-Cleaveland K, et al. Fertility and contraceptive use among young adults in Harare, Zimbabwe. Stud Fam Plann 1991; 22:264-271.

4. Topouzis D. The Socio-Economic Impact of HIV/AIDS on Rural Families with Emphasis on Youth. Rome: Food and Agricultural Organisation of the United Nations, 1994.

5. Sicard J, Kanon S, Quedraogo L, et al. The evaluation of sexual behavior and knowledge of AIDS in the schools in Burkina Faso. A knowledge, attitude, belief and practice (KABP) survey in Banfora among 474 adolescents of 1425 years old. Ann Soc Belge Med Trop 1992;72: 63-72.

6. Kamtchouing P, Ngoh N and Yakam I. Sexuality of adolescent students in Yaounde (Cameroon). Contracep Fert Sexual 1997; 25: 798-801.

7. Stevenson W, Maton K and Teti D. School importance and dropouts among pregnant adolescents. J AdolHealth 1998; 22:376-382.

8. Lawal R, Adelekan M, Ohaeri J, et al. Rehabilitation of heroin and cocaine abusers managed in a Nigerian psychiatric hospital. $E$ AfrMedJ 1998; 75: 107-112.

9. Nichols D, Ladipo O, Paxman J, et al. Sexual behavior, contraceptive practices, and reproductive health among Nigerian adolescents. Stud Fam Plann 1986; 17: 100-106.

10. Adeokun L. Household functioning and AIDS,
Vol. 8. Quantitative data: combined 3-district report (Masaka, Kabarole, Rukungiri). Institute of Statistics and Applied Economics, Makerere University, Kampala, Uganda, 1996.

11. Tindyebwa D. Contraceptive prevalence in Kabarole district. Unpublished report, District Health Office, Fort Portal, Uganda, 1996.

12. World Health Organization. Practical Guide for Health Workers on Interviewing and Recording of Community Health Surveys. Geneva: World Health Organization, 1986.

13. Barongo L, Rugemalia J, Gabone R, et al. Kagera 1989 health survey: 1. Hum a immunodeficiency virus seroprevalence in adolescents. E AfrMedJ 1992; 69: 323-326.

14. Knaul $G$ and Rich S. Influences on adolescent sexuality in Nigeria and Kenya: Findings from recent focus-group discussions. Stud Fam Plann 1992; 23: 199-210.

15. Kilian A, Gregson S, Ndyanabangi B, et al. Reductions in risk behavior provide the most consistent explanation for declining HIV-1 prevalence in Uganda. AIDS 1999; 13: 391-398.

16. Statistics Department, Ministry of Planning, Financing and Economic Development, Kampala, Uganda and Macro International Inc., Calverton, Maryland. Demographic and Health Survey 1995.

17. Menick D and Ngoh F. Sexual abuse in children in Cameroon. Med Trop 1998; 58: 249-252.

18. Hughes $\mathrm{J}$ and McCauley A. Improving the fit: adolescents'needs and future programs for sexual and reproductive health in developing countries. Stud Fam Plann 1998; 29: 233-245. 